\title{
Frozen yogurt with added inulin and isomalt
}

\author{
U. Isik, ${ }^{1}$ D. Boyacioglu, ${ }^{2}$ E. Capanoglu, and D. Nilufer Erdil \\ Istanbul Technical University, Faculty of Chemical and Metallurgical Engineering, Food Engineering Department, 34469, Maslak, Istanbul, Turkey
}

\begin{abstract}
The objective of this study was to produce a frozen yogurt containing low fat and no added sugar. Samples containing $5 \%$ polydextrose, $0.065 \%$ aspartame and acesulfame-K mixture, and different levels of inulin and isomalt $(5.0,6.5$, and $8.0 \%)$ were produced at pilot scale and analyzed for their physical and chemical properties including proximate composition, viscosity, acidity, overrun, melting rate, heat shock stability, as well as sensory characteristics, and viability of lactic acid bacteria. With the addition of inulin and isomalt, viscosity increased by 19 to $52 \%$ compared with that of sample B (reduced-fat control). The average calorie values of samples substituted with sweeteners were about $43 \%$ lower than that of original sample. Low-calorie frozen yogurt samples melted about 33 to $48 \%$ slower than the reduced-fat control sample at $45 \mathrm{~min}$. Based on quantitative descriptive profile test results, statistically significant differences among products were observed for hardness, iciness, foamy melting, whey separation, and sweetness characteristics. The results of principal component analysis showed that the sensory properties of the sample containing $6.5 \%$ inulin and $6.5 \%$ isomalt were similar to those of control. Lactic acid bacteria counts of frozen yogurt were found to be between 8.12 and $8.49 \mathrm{log}$ values, $3 \mathrm{mo}$ after the production. The overall results showed that it is possible to produce an attractive frozen yogurt product with the incorporation of inulin and isomalt with no added sugar and reduced fat.
\end{abstract}

Key words: frozen yogurt, inulin, isomalt

\section{INTRODUCTION}

Frozen yogurt as also known as yogurt ice cream, characterized by the acidic taste of yogurt and the cooling effect of ice cream (Tamime and Robinson, 1999), is a dairy product produced with Streptococcus

Received March 22, 2010.

Accepted January 1, 2011.

${ }^{1}$ Current address: Erciyes Technopark, Inc., Erciyes University, Technology Development Zone-I 38039, Kayseri, Turkey.

${ }^{2}$ Corresponding author: boyaci@itu.edu.tr thermophilus or Lactobacillus delbrueckii spp. bulgaricus (Hui, 1992; Marshall et al., 2003). Survival of yogurt cultures in frozen yogurt has great importance for the therapeutic image of the product, as yogurt has been a healthful product with high biological value (Tamime and Robinson 1999) and probable benefits, which are improvement of the immune system by destruction of bacterial cells, lactose digestion, regularity of intestinal flora, detoxification of harmful products, reduction of carcinogenic end products, and suppressing the multiplication of food-sourced pathogens (Hui, 1993). In addition, frozen yogurt is expected to present acceptable quality of flavor, body, texture, cooling effect, viscosity, whipping ability, and freezing properties of dairy frozen desserts (Chandan, 1997).

Several researchers focused on producing functional frozen yogurt or yogurt ice cream containing stabilizers (Martinou-Voulasiki and Zerfiridis, 1990), inulin (ElNagar et al., 2002), fat-replacers (Kaur et al., 2007; Aykan et al., 2008), or different hydrocolloids (Soukoulis and Tzia, 2008), and several others investigated the characteristics of these products (Inoue et al., 1998; Zhenjian and Haili, 2003; Özdemir et al., 2005; Singh et al., 2006; Guner et al., 2007). However, limited information is available on the properties of functional frozen yogurt having fat and sugar replacements.

To produce a low-calorie frozen yogurt, inulin and sugar alcohols deserve particular attention. Inulin, a soluble dietary fiber, can be used to improve the quality of the product with nutritional and technological advantages (Franck, 1998; Rowan, 1998). Addition of inulin in low-fat frozen yogurt formulation (El-Nagar et al., 2002) or using inulin as a corn syrup replacer in reduced-fat ice cream (Schaller-Povolny and Smith, 1999, 2001, 2002) are good examples of its application in frozen desserts. On the other hand, sugar alcohols, such as isomalt, are used as sugar replacers in frozen desserts (Marshall and Goff, 2003) for their low glycemic index (Macrae et al., 1993) and low caloric value (McNutt and Sentko, 1996).

The objective of this study was to produce a lowcalorie frozen yogurt containing reduced fat and no added sugar, which were replaced with inulin, isomalt, polydextrose, and intensive sweeteners, and having acceptable rheological and sensory attributes. 
Table 1. Frozen yogurt formulations ${ }^{1}$

\begin{tabular}{|c|c|c|c|}
\hline Sample & Description & $\underset{(\%)}{\text { Inulin }}$ & $\begin{array}{c}\text { Isomalt } \\
(\%)\end{array}$ \\
\hline A & Control (with sugar and whole fat) & - & - \\
\hline B & Control (with sugar and reduced fat) & - & - \\
\hline $\mathrm{C}$ & No sugar and reduced fat & 8.0 & 5.0 \\
\hline $\mathrm{D}$ & No sugar and reduced fat & 6.5 & 6.5 \\
\hline $\mathrm{E}$ & No sugar and reduced fat & 5.0 & 8.0 \\
\hline
\end{tabular}

\section{MATERIALS AND METHODS}

\section{Ingredients}

Food additives were polydextrose (Litesse-Ultra, Danisco Sweeteners, Copenhagen, Denmark), inulin (Raftiline GR, Dora Company, Istanbul, Turkey), and isomalt (Palatinit ST-PF, Kurmed Company Ltd., Istanbul, Turkey). Starter cultures (MYE-96), yogurt and thermophilic culture development medium (Thermo W1) were obtained from the Maysa Company, Istanbul, Turkey. All of the production trials were carried out at pilot scale in a commercial ice cream manufacturing plant in Turkey.

\section{Experimental Design}

Before starting to produce different formulations of frozen yogurt samples ( 5 different formulations as described in Table 1), the optimum $\mathrm{pH}$ value of the product (control sample formulation, sample A in Table 1) was evaluated by conducting a consumer preference and acceptance test (Meilgaard et al., 2007). Forty kilograms of samples having 2 different $\mathrm{pH}$ values $(\mathrm{pH} 4.8$ and 5.2) were produced and evaluated by 88 panelists using a simple comparison sensory test. In the test, one sample pair was provided for each panelist by balancing the presentation of samples and then the panelists were asked for their preference, degree of liking, and purchase intent for the preferred sample. The degree of liking was evaluated on a category scale composed of 7 scores: 1 (extremely dislike), 2 (dislike), 3 (slightly dislike), 4 (neither like nor dislike), 5 (lightly like), 6 (like), and 7 (extremely like). In addition, the panelists were asked to evaluate their purchase intent on a category scale composed of 5 points: 1 (definitely will not buy), 2 (probably will not buy), 3 (not sure), 4 (will probably buy), and 5 (will definitely buy).

Based on the preference of the panelists, the $\mathrm{pH}$ value of the samples was determined, and 5 new formulations were prepared using $40-\mathrm{kg}$ batches (Table 1). These samples were further analyzed for their composition, viscosity, melting rate, sensory characteristics, and lactic acid bacteria (LAB) count.

\section{Frozen Yogurt Production}

Ingredients were weighed to obtain a 40-kg mixture for each batch of production. The formula of frozen yogurt samples used in the study was designed according to the original recipes of a commercial ice cream manufacturing plant in Turkey (Algida, Unilever Inc., Tekirdağ). Nonfat milk solids (10.5\%), sweetening agents (sugar or inulin + isomalt + polydextrose + aspartame + acesulfame-K, Raftiline GR, Dora Company; Palatinit St-PF, Kurmed Company Ltd.; Litesse-Ultra, Danisco Sweeteners), and stabilizer mixture $(0.1 \%$ locust bean gum $+0.1 \%$ guar gum $+0.1 \%$ carboxymethylcellulose + $0.03 \%$ carrageenan $+0.3 \%$ emulsifier; Algida, Unilever Inc.) were incorporated with cream and water in a mixing tank. Then, the mixture was heated at $85^{\circ} \mathrm{C}$ for 10 min and homogenized under a pressure of 190 bar. The mixture was cooled down to $44^{\circ} \mathrm{C}$ and transferred into a sterile container (approximately $37-\mathrm{kg}$ mix). Following the inoculation of $5 \%$ starter culture, the mixture was incubated at $40^{\circ} \mathrm{C}$ until a $\mathrm{pH}$ value of 5.2 was reached. The samples with a $\mathrm{pH}$ of 4.8 used for the consumer preference and acceptance test were also produced in the same manner. The cultured mixture was placed in a resting tank and cooled down to $5^{\circ} \mathrm{C}$ while stirring. Vanilla flavor $(0.1 \%$; oil-soluble, nature-identical flavor, Aromsa Food Flavor and Additives Co., Inc., Istanbul, Turkey) was added at this stage, and cultured mixture was pumped into the ice cream freezer (Hoyer freezer MF50, APV Technohoy, Axel Kiers Vej 28-30, Aarhus-Højbjerg, Denmark) where the temperature of the samples reached $-6^{\circ} \mathrm{C}$. The samples were then packed into 1-, 2-, and 5-L plastic cups and placed in a freezer at $-23^{\circ} \mathrm{C}$. The samples were then transferred from Algida, Unilever Inc., to the laboratories of Istanbul Technical University (Turkey) and stored at $-18^{\circ} \mathrm{C}$ until analysis. 


\section{Starter Culture Propagation}

Main yogurt cultures used to prepare the intermediate cultures were obtained in freeze-dried form (MYE-96, Maysa Company). The processing culture used for the production of frozen yogurt samples was prepared from this intermediate culture under sterile conditions (Istanbul Trade Organization, 1985). In the preparation of intermediate culture, thermophilic culture development medium (Thermo W1) was used instead of milk. Sixty grams of medium was dissolved in $940 \mathrm{~g}$ of water and heated up to $90^{\circ} \mathrm{C}$ while stirring. After keeping at $90^{\circ} \mathrm{C}$ for $10 \mathrm{~min}$, the medium was cooled down to $45^{\circ} \mathrm{C}$. Main culture $(0.02 \mathrm{~g}$ of main culture for $1 \mathrm{~kg}$ of milk that has been treated at $90^{\circ} \mathrm{C}$ for 10 to $15 \mathrm{~min}$ ) was added to the mixture at $45^{\circ} \mathrm{C}$, incubated for $4 \mathrm{~h}$ at $43^{\circ} \mathrm{C}$ and stored at $4^{\circ} \mathrm{C}$. Intermediate culture preparation was repeated for every week of production.

Processing cultures were prepared separately for each batch, the day before production. Two hundred sixtyfour grams of nonfat milk solids was added to 1,936 g of water to obtain $12 \%$ total solids and mixed for 2 min. Then, it was prepared similarly to the intermediate culture, except for adding 3\% intermediate culture (66 g) instead of the main culture. The $\mathrm{pH}$ was tracked using a hand $\mathrm{pH}$ meter (MP120 pH meter, Mettler-Toledo GmbH, Schwerzenbach, Switzerland) and the mix was cooled as the $\mathrm{pH}$ reached 4.6 and stored at $4^{\circ} \mathrm{C}$ the day before production. Processing culture $(5 \%)$ was added to the frozen yogurt mix (weighed as approximately 37 $\mathrm{kg}$ after the pasteurization and homogenization steps).

\section{Analysis of Composition and Calculation of Overrun}

Sample preparation was performed according to AOAC, 969.20 (AOAC, 2002). Total solids and protein analyses were based on AOAC 941.08 and 930.33 (AOAC, 2002), respectively. Ash content and acidity were analyzed using AOAC methods 945.46 and 947.05, respectively (AOAC, 2002). Fat content was analyzed by Turkish Standard (TS) method 4265 (TSE, 1992). Carbohydrate content was determined by the calculation method and the calorie values were calculated according to the energy conversion factors in the Turkish Food Codex (Notice No. 2002/58; Turkish Ministry of Agriculture, 2002). Based on the Codex, the conversion factor for carbohydrates (excluding sugar alcohols) is $4 \mathrm{kcal} / \mathrm{g}$; for sugar alcohols, $2.4 \mathrm{kcal} / \mathrm{g}$; for proteins, 4 $\mathrm{kcal} / \mathrm{g}$; for fats, $9 \mathrm{kcal} / \mathrm{g}$ (Turkish Ministry of Agriculture, 2002); for inulin, $1.5 \mathrm{cal} / \mathrm{g}$ (Boeckner et al., 2001); and for polydextrose, $1 \mathrm{kcal} / \mathrm{g}$ (Craig, 2000). Overrun values of the samples were calculated according to the method by Goh et al. (2008).

\section{Analyses of Viscosity and Melting Rate}

Before freezing, viscosities of the frozen yogurt mixtures were measured for each batch using a Brookfield Viscometer (model DV-II, spindle no. 3 at $30 \mathrm{rpm}$ at $5^{\circ} \mathrm{C}, 12 \mathrm{rpm}$ at $6^{\circ} \mathrm{C}$, and $6 \mathrm{rpm}$ at $5.5^{\circ} \mathrm{C}$ ) with 3 replications, according to Martinou-Voulasiki and Zerfiridis (1990) and El-Nagar et al. (2002).

For the melting rate test, a 2.5-mm iron wire mesh screen (Analysensieb, Retsch, D-5657 Haan, Germany) was used. The test was carried out according to the method of El-Nagar et al. (2002) with small modifications. Forty grams of cubic cut sample was placed on the screen, which was mounted on a beaker. The weight of the collected sample in the beaker was recorded at min 15, 30, and 45 of melting. The ratio of these values to the initial weight of frozen yogurt was calculated.

\section{Quantitative Descriptive Profile Test}

The sensory characteristics of the samples, including flavor, texture, and melting quality were evaluated by 9 trained panelists from the Department of Food Engineering of Istanbul Technical University. The samples that were stored at $-18^{\circ} \mathrm{C}$ were taken out of the freezer and kept outside for approximately 5 min to reach the serving temperature of $-15^{\circ} \mathrm{C}$ for the sensory analysis, as suggested by Hui (1993). The quantitative descriptive profile test (QDPT) was performed according to Meilgaard et al. (2007) and the quantitative descriptive analysis (QDA) method was applied according to Guinard et al. (1997) and Poste et al. (1991). Panelists were trained for $8 \mathrm{~h}$ at 4 sessions.

For the first training session, a terminology list for the texture and flavor attributes of frozen yogurt was prepared, combining the characteristics of ice cream and yogurt (Harper et al., 1991; Hui, 1992, 1993; Specter and Setser, 1994; Guinard et al., 1997; Davidson et al., 2000; Prindiville et al., 2000). The references that best described the product were selected from the literature (Harper et al., 1991; Guinard et al., 1997; Prindiville et al., 1999, 2000; Meilgaard et al., 2007); however, the panelists were free to give their own terms.

At the second training session, the list of terms was revised and the panelists were trained for using an unstructured line scale. The intensity of each reference was judged on an unstructured scale consisting of a horizontal 15-cm line (anchored by the words "none" and "very" at the 2 ends) by consensus of the panelists. The reference samples were supplied during each session.

The third training session was carried out in 3 stages; the first stage involved the individual evaluation of one 
attribute of texture (creaminess) and one flavor characteristic (sweetness) using the reference samples; the second stage included the individual evaluation of all attributes for 2 samples with $\mathrm{pH}$ values of 4.8 and 5.2; and, at the third stage, a set of criteria for melting quality was developed by the panelists because no suitable references exist for this attribute.

Quantitative descriptive profile test sessions were performed in separate booths, and no special lighting (fluorescent lights) was used. To prevent the fatigue of the panelists, 5 samples were presented at each session and repeated 2 times. One ice cream spoonful of sample, which is approximately $30 \mathrm{~g}$, was placed in each 150-mL plastic cup, covered, and stored in the freezer $\left(-18^{\circ} \mathrm{C}\right)$ before analysis. Water and crackers with no sugar were served to the panelists to condition their mouths between testing of each sample. Frozen yogurt attributes, definitions, and references that were used in sensory analysis are given in Table 2 .

\section{Analysis of Lactic Acid Bacteria Count}

Lactic acid bacteria count was performed in 2 parallels using the pour-plate method involving Elliker broth (Erkmen, 2000; Downes and Ito, 2001). Colonies were counted on the second day of incubation at $30^{\circ} \mathrm{C}$. For the analysis, $25 \mathrm{~g}$ of frozen yogurt for each sample was weighed into the stomacher and placed in the freezer $\left(0^{\circ} \mathrm{C}\right)$, and the dilutions in the range of $10^{-1}$ to $10^{-7}$ were prepared. Two hundred and fifty milliliters of $0.1 \%$ peptone water was added to the samples, which were then placed on a hot plate $\left(45^{\circ} \mathrm{C}\right.$ for $\left.15 \mathrm{~s}\right)$ and homogenized for 2 min. (Erkmen, 2000; Downes and Ito, 2001).

\section{Statistics}

The results of the consumer preference and acceptance test that was performed to select the optimum $\mathrm{pH}$ value were evaluated according to the significance $(P<0.05)$ of preference values in the statistical tables of Meilgaard et al. (2007). The differences in scores of flavor, texture, and appearance, as well as consumer purchase intent of samples, were evaluated by $t$-test with Minitab 14.10 statistical software (Minitab Inc., State College, PA; $P<0.05)$. The differences in viscosity, LAB count, and overrun among formulations were investigated with completely randomized design with SPSS 9.0 statistical software (SPSS Inc., Chicago, IL) and the means were compared using the least significant difference test $(P<0.05)$. Principal component analysis (PCA) of QDPT was performed by Minitab 14.10 software (Minitab Inc.) using a correlation matrix. For the 5 formulations (A, B, C, D, and E) mean values of the scores of flavor, texture and melting quality were determined and PCA was applied to this matrix.

\section{RESULTS AND DISCUSSION}

In the study, the preliminary consumer preference and acceptance test was performed to determine the $\mathrm{pH}$ value ( $\mathrm{pH} 4.8$ or 5.2) according to the preference of the consumers. The results showed that $69 \%$ of the panelists preferred the sample having a $\mathrm{pH}$ value of 5.2 in comparison to the sample with $\mathrm{pH} 4.8$ (data not shown). As the preference of the panelists was statistically significant $(P<0.05)$, the $\mathrm{pH}$ of samples was adjusted to 5.2 in the following stages of the study. It is known that the $\mathrm{pH}$ value of frozen yogurt samples can be in a range of 4.3 to 5.3 and even in some cases between 4.0 and 5.7, based on the consumer's preference (Martinou-Voulasiki and Zerfiridis, 1990). Similar to our findings, the study of Inoue et al. (1998) showed that the highest total sensory scores were given to the sample having a $\mathrm{pH}$ of 5.5. The purchase intent of the preferred sample was between 4 (probably buy) or 5 (definitely buy) on a category scale (data not shown).

The compositions of all formulations were determined (data not shown). According to the results, the average total solid and fat contents of the control and reducedfat samples were found to be 30.1 and $33.1 \%$, and 3.2 and $6.1 \%$, respectively. The average protein, ash, and carbohydrate contents of the control sample were 3.3, 0.9 , and $22.8 \%$, respectively. These results are in accordance with the values reported in the literature, where fat, protein, ash, and total solids contents were in the range of 1.8 to $5.9 \%, 3.5$ to $3.8 \%, 0.7$ to $1.0 \%$, and 28.8 to $34.2 \%$, respectively (Tamime and Robinson, 1999; Tamime, 2006).

Acidity of the samples was in between 0.69 and $0.72 \%$ in terms of lactic acid (data not shown). Similar values were reported by Guner et al. (2007) who reported that lactic acid levels higher than $0.7 \%$ caused progressive loss of sensory quality in the frozen yogurt samples. On the other hand, the $\mathrm{pH}$ of each formulation was adjusted to 5.2, and was controlled for each formulation during production.

Overrun is one of the most important characteristics of frozen desserts (Marshall et al., 2003), and it affects the texture as well as the price of the product. The targeted overrun in frozen yogurt samples was $80 \%$, and it was observed to be between 70 and $78 \%$, without any significant differences among the samples $(P<0.05)$.

The reduced-fat control sample (B) had a $15 \%$ lower energy value in comparison to the whole-fat control sample (A; Table 3). Also, the calorie values of samples $\mathrm{C}, \mathrm{D}$, and $\mathrm{E}$ were decreased by about $33 \%$ in comparison to sample B. On the other hand, the average calorie 
Table 2. Frozen yogurt attributes of texture, flavor, and melting quality in addition to their definitions and references used for scaling

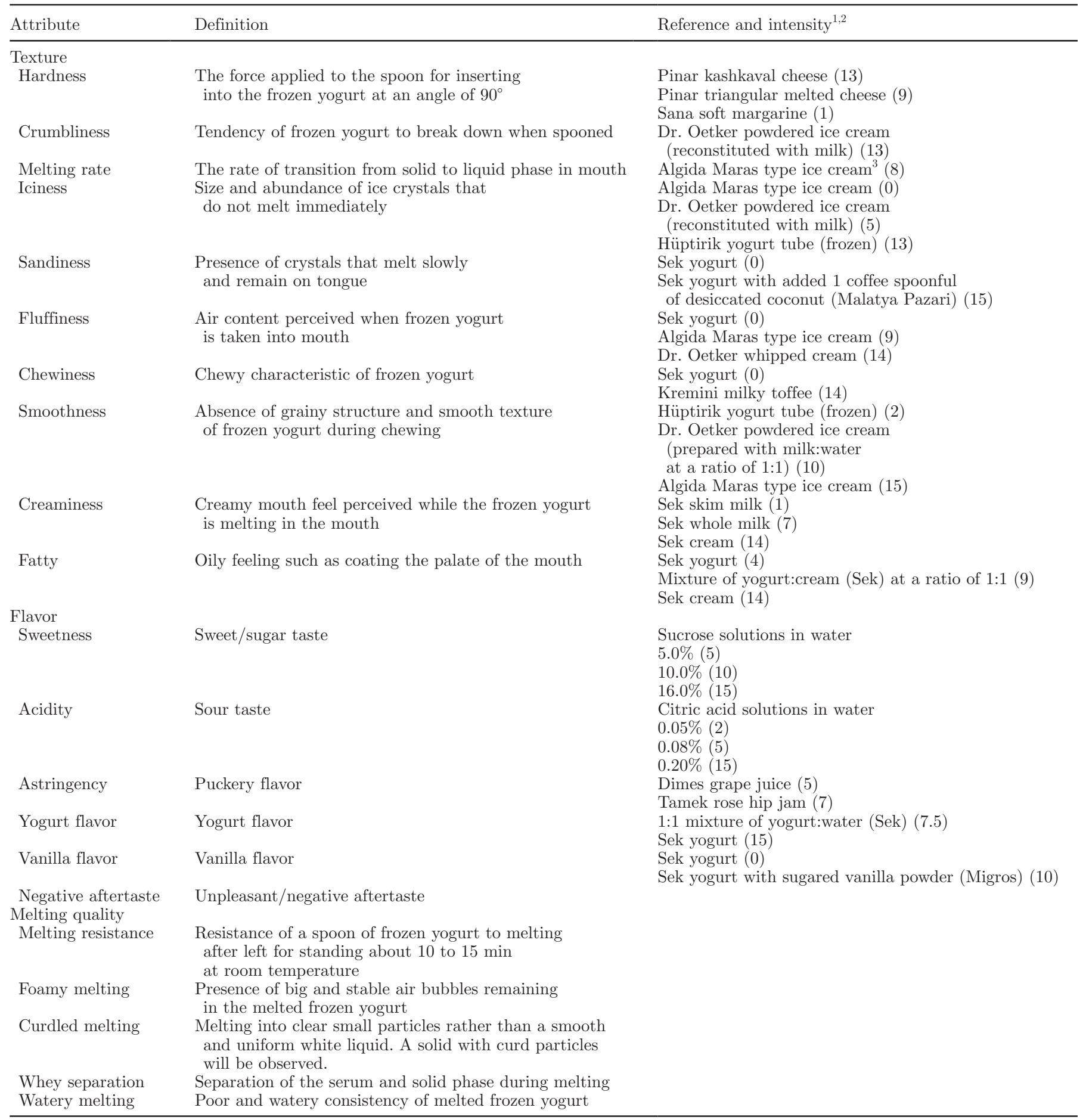

${ }^{1}$ Numbers shown in parenthesis for the references indicate the intensity of the reference on an unstructured scale consisting of a horizontal 15 -cm line anchored with the words "none" and "very" at the ends.

${ }^{2}$ References: Algida Maras type ice cream, Kremini (milky chewy candy/toffee), Dr. Oetker ice cream powder, Dr. Oetker whipped cream powder, Hüptirik yogurt tube (frozen), Sek yogurt, skim milk, whole milk, cream, Dimes grape juice, Tamek rose hip jam, Migros powdered sugar with vanilla, citric acid and sucrose solutions. The references were obtained from a local supermarket in Istanbul, Turkey.

${ }^{3}$ Algida Maras type ice cream is a commercial product that is characterized by its smooth structure. 
Table 3. Texture, flavor, and melting quality scores of frozen yogurt samples ${ }^{1}$

\begin{tabular}{|c|c|c|c|c|c|}
\hline Attribute & \multicolumn{5}{|c|}{ Sample } \\
\hline \multicolumn{6}{|l|}{ Texture } \\
\hline Crumbliness & $9.0 \pm 2.6^{\mathrm{a}}$ & $9.2 \pm 3.1^{\mathrm{a}}$ & $9.3 \pm 3.4^{\mathrm{a}}$ & $8.4 \pm 4.1^{\mathrm{a}}$ & $9.3 \pm 3.5^{\mathrm{a}}$ \\
\hline Melting rate & $9.4 \pm 2.3^{\mathrm{a}}$ & $9.8 \pm 2.3^{\mathrm{a}}$ & $9.8 \pm 1.9^{\mathrm{a}}$ & $10.0 \pm 2.2^{\mathrm{a}}$ & $9.8 \pm 2.4^{\mathrm{a}}$ \\
\hline Iciness & $4.0 \pm 2.5^{\mathrm{b}}$ & $4.7 \pm 2.7^{\mathrm{ab}}$ & $4.3 \pm 2.7^{\mathrm{ab}}$ & $3.9 \pm 2.5^{\mathrm{b}}$ & $5.5 \pm 2.8^{\mathrm{a}}$ \\
\hline Smoothness & $12.3 \pm 2.0^{\mathrm{a}}$ & $11.3 \pm 2.8^{\mathrm{a}}$ & $12.1 \pm 2.3^{\mathrm{a}}$ & $12.5 \pm 2.0^{\mathrm{a}}$ & $11.5 \pm 2.7^{\mathrm{a}}$ \\
\hline Creaminess & $8.3 \pm 3.2^{\mathrm{a}}$ & $7.6 \pm 3.3^{\mathrm{a}}$ & $8.2 \pm 2.9^{\mathrm{a}}$ & $7.7 \pm 3.4^{\mathrm{a}}$ & $8.0 \pm 3.3^{\mathrm{a}}$ \\
\hline Oiliness & $7.8 \pm 2.3^{\mathrm{a}}$ & $7.2 \pm 2.4^{\mathrm{a}}$ & $7.8 \pm 2.4^{\mathrm{a}}$ & $7.6 \pm 2.4^{\mathrm{a}}$ & $7.9 \pm 2.3^{\mathrm{a}}$ \\
\hline \multicolumn{6}{|l|}{ Flavor } \\
\hline Sweetness & $7.4 \pm 1.6^{\mathrm{b}}$ & $7.3 \pm 1.9^{\mathrm{b}}$ & $7.9 \pm 1.8^{\mathrm{ab}}$ & $7.5 \pm 1.7^{\mathrm{b}}$ & $8.5 \pm 2.0^{\mathrm{a}}$ \\
\hline Acidity & $4.2 \pm 1.6^{\mathrm{a}}$ & $4.1 \pm 1.7^{\mathrm{a}}$ & $4.2 \pm 1.9^{\mathrm{a}}$ & $3.9 \pm 1.9^{\mathrm{a}}$ & $4.1 \pm 2.0^{\mathrm{a}}$ \\
\hline Melting resistance & $7.7 \pm 2.6^{\mathrm{a}}$ & $7.8 \pm 2.9^{\mathrm{a}}$ & $7.3 \pm 2.8^{\mathrm{a}}$ & $6.8 \pm 3.1^{\mathrm{a}}$ & $7.2 \pm 3.1^{\mathrm{a}}$ \\
\hline Foamy melting & $0.3 \pm 0.8^{\mathrm{b}}$ & $1.0 \pm 1.3^{\mathrm{a}}$ & $0.4 \pm 0.8^{\mathrm{ab}}$ & $0.4 \pm 0.6^{\mathrm{b}}$ & $0.4 \pm 0.9^{\mathrm{ab}}$ \\
\hline Curdled melting & $7.5 \pm 3.2^{\mathrm{a}}$ & $7.2 \pm 3.2^{\mathrm{a}}$ & $8.8 \pm 2.8^{\mathrm{a}}$ & $7.2 \pm 4.1^{\mathrm{a}}$ & $8.6 \pm 3.4^{\mathrm{a}}$ \\
\hline Whey separation & $6.2 \pm 4.1^{\mathrm{ab}}$ & $6.3 \pm 4.1^{\mathrm{ab}}$ & $7.6 \pm 4.0^{\mathrm{ab}}$ & $5.8 \pm 4.2^{\mathrm{b}}$ & $8.1 \pm 4.2^{\mathrm{a}}$ \\
\hline Watery melting & $6.9 \pm 2.8^{\mathrm{a}}$ & $7.3 \pm 2.6^{\mathrm{a}}$ & $7.4 \pm 3.1^{\mathrm{a}}$ & $7.3 \pm 3.3^{\mathrm{a}}$ & $7.3 \pm 2.8^{\mathrm{a}}$ \\
\hline
\end{tabular}

${ }^{\mathrm{a}, \mathrm{b}}$ Values having different letters in rows are significantly different $(P<0.05)$.

${ }^{1}$ Values represent the means and standard deviations of 4 replications with 9 panelists $(\mathrm{n}=36$ ). Sample A $=$ control (with sugar and whole fat), sample B = control (with sugar and reduced fat). Samples C-E had no sugar and reduced fat, and contained $5 \%$ polydextrose and $0.065 \%$ aspartame/acesulfame-K mixture (at a proportion of 70:30). Sample C also contained $8.0 \%$ inulin and $5.0 \%$ isomalt; sample D contained $6.5 \%$ inulin and $6.5 \%$ isomalt; and sample E contained $5.0 \%$ inulin and $8.0 \%$ isomalt.

values of samples substituted with sweeteners (C, D, and E) were about $43 \%$ lower than that of the control sample A (containing sugar). Therefore, these samples could be defined as low calorie according to the Turkish Food Codex, where low-calorie foods are expected to have $25 \%$ lower calorie values in comparison with the original formulation (control; Turkish Ministry of Agriculture, 2002).

The viscosity values of all formulations are shown in Figure 1. Viscosities of 5 formulations showed statistically significant differences $(\mathrm{A}>\mathrm{C}>\mathrm{D}>\mathrm{E}>\mathrm{B})$ from each other $(P<0.05)$. The viscosity of the reduced-fat control sample (B) was significantly lower (38-46\%) than that of the whole-fat control sample (A). Because the sucrose amount (18\%) is identical in both samples, the viscosity decrease may be associated with the decreased fat and total solid contents. On the other hand, the viscosities of low-calorie products $(\mathrm{C}, \mathrm{D}$, and $\mathrm{E})$ were observed to be higher $(29.8,19.3$, and $15.4 \%$, on average, respectively) than that of the reduced-fat control sample (B). As the total solids and polydextrose levels are constant in the samples having no sugar and reduced fat, the variation in viscosities among these samples $(\mathrm{C}>\mathrm{D}>\mathrm{E})$ are expected to be related to the addition of inulin and isomalt ingredients. The ad- dition of inulin and isomalt increased the viscosity of samples C, D, and E at a level of 52, 27, and 19\%, respectively, in comparison to the reduced-fat control at $6 \mathrm{rpm}\left(5.5^{\circ} \mathrm{C}\right.$; Figure 1). However, the viscosities of those samples were lower by about 18.3 to $32.8 \%$ than that of the whole-fat control sample (Figure 1). Schaller-Povolny and Smith (2001) observed that the substitution of corn syrup with inulin increased the viscosity and the consistency of the fat-reduced ice cream samples. In another study, investigating the effects of inulin and whey protein concentrate on the physicochemical properties of mango flavored frozen yogurt, it was observed that incorporation of inulin increased the viscosity, whereas supplementation with whey protein concentrate alone decreased it (Kaur et al., 2007). Increased viscosity in the reduced-fat samples containing inulin can be explained by the interactions of the dietary fiber and liquid components of the frozen yogurt mix. Inulin, being highly hygroscopic, would bind water and form a gel-like network that, in addition to the other components, would modify the rheology of the mix (El-Nagar et al., 2002).

The results of the melting rate measurements are shown in Figure 2. The most rapid melting was observed in the reduced-fat sample B (71\% at min 45$)$ having de- 


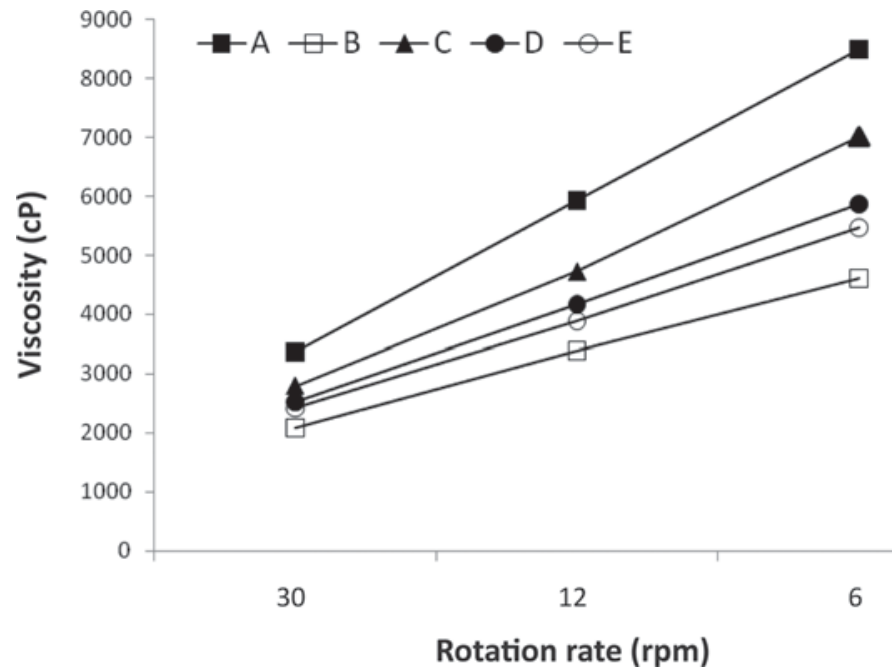

Figure 1. Viscosity of yogurt ice cream samples $(\mathrm{n}=6)$. Sample A $=$ control (with sugar and whole fat), sample B = control (with sugar and reduced fat). Samples C-E had no sugar and reduced fat, and contained $5 \%$ polydextrose and $0.065 \%$ aspartame/acesulfame-K mixture (at a proportion of 70:30). Sample C also contained $8.0 \%$ inulin and $5.0 \%$ isomalt; sample D contained $6.5 \%$ inulin and $6.5 \%$ isomalt; and sample E contained $5.0 \%$ inulin and $8.0 \%$ isomalt.

creased levels of fat and total solid amounts compared with the control sample (A). Low-calorie frozen yogurt samples (C, D, and E) melted more slowly (33-48\% at min 45) than did the reduced-fat control (B); on the other hand, particularly samples D and E melted more rapidly (50 and $44 \%$, respectively) than did the whole-fat control sample $(\mathrm{A})$, which had a melting rate of $32 \%$ at min 45 . (Figure 2). Sample C, having the



Figure 2. Melting rates of yogurt ice cream samples measured at $\min 15,30$, and 45 . Values represent the means of 4 replications (n $=4$ ). Sample $\mathrm{A}=$ control (with sugar and whole fat), sample $\mathrm{B}=$ control (with sugar and reduced fat). Samples C-E had no sugar and reduced fat, and contained $5 \%$ polydextrose and $0.065 \%$ aspartame/ acesulfame-K mixture (at a proportion of 70:30). Sample C also contained $8.0 \%$ inulin and $5.0 \%$ isomalt; sample D contained $6.5 \%$ inulin and $6.5 \%$ isomalt; and sample E contained $5.0 \%$ inulin and $8.0 \%$ isomalt. highest inulin and lowest isomalt levels, was evaluated to be the closest product to the control sample (A), because of its low melting rate and similar melting trends. In the melting test, the first drip points of samples were also measured. The first drip points, in terms of minutes, were in the order of $\mathrm{A}(13.5)>\mathrm{C}(11.5)>$ D (10.8) > B (9.8) > E (8.5). Based on the first drip point value, sample $\mathrm{C}$ was again observed to be similar to the control sample (A). Melting rate and the appearance of the melted mix are considered significant characteristics of ice cream (Hui, 1993). Melting rate is especially important when the ice cream is consumed in an ice cream cone. Rapid melting of the product is an indicator of low quality, and such products would also cause problems, as they will easily be affected by heat shock. Products having too much air or fat tend to melt slowly. Air bubbles act as an isolation material and fat stabilizes the foam structure (Marshall et al., 2003).

The sensory scores measured by the QDPT test are presented in Table 3. Statistically significant differences among products were only found for the characteristics including hardness, iciness, sweetness, foamy melting, and whey separation $(P<0.05)$. Except for the foamy melting attribute, no significant difference in any of the sensory characteristics between control samples A and $\mathrm{B}$ were found $(P<0.05)$. Sample $\mathrm{C}$ and $\mathrm{E}$ had the highest levels of the hardness textural attribute, which are followed by the order $\mathrm{B}>\mathrm{D}>\mathrm{A}$. The hardness characteristic was found to be statistically different in sample $\mathrm{E}$ in comparison with the samples $\mathrm{A}$ and $\mathrm{B}(P$ $<0.05)$. The lowest level of iciness was observed for sample D among the low-calorie formulations, which was not statistically different from the control sample (A). However, the difference in the iciness attribute was statistically significant between samples D and E $(P<$ 0.05; Table 3).

Isomalt addition at a level of $8.0 \%$ (sample E) resulted in significantly higher sweetness scores $(P<$ 0.05 ). However, no significant difference was observed in sweetness of samples C (5\% isomalt) and D (6.5\% isomalt) compared with the control samples (Table 3 ). Several studies have pointed out the advantages of using isomalt in different food materials, such as the improvement of the sensory attributes and contribution to the nutritive value (McNutt and Sentko, 1996; Gostner et al., 2006; Radowski, 2006).

According to the scores of melting quality, foamy melting, and whey separation, properties were significantly different between samples $(P<005$; Table 3$)$. Sample $B$ (reduced-fat control) had the highest foamy melting characteristic, which was found to be statistically different from samples A and D $(P<0.05)$, although no significant difference between the rest of the samples was present. In addition, whey separation was highest 
in sample E and lowest in sample D (Table 3) and the difference between these samples was statistically significant $(P<0.05)$, whereas no differences between samples $\mathrm{A}, \mathrm{B}$, and $\mathrm{C}$ were observed. Contrary to the proposal of El-Nagar et al. (2002), indicating a clear relationship between increased inulin levels and improved melting properties in frozen yogurt, no significant effect of inulin addition on melting attributes was observed $(P<0.05)$ in this study.

These results showed that inulin addition in a range of 6.5 to $8.0 \%$ slightly affected the sensory attributes of frozen yogurt samples. Akin (2005) reported that the addition of inulin improved viscosity, first dripping, and complete melting times, but had no effect on the sensory properties of probiotic fermented ice-cream. In another study, a good quality frozen yogurt was prepared by blending inulin at a level of $3 \%$ in yogurt mix. However, the results of this study showed that the sensory properties of frozen yogurt were improved with increased fat and nonfat solids content (Kaur et al., 2007). On the other hand, according to Aykan et al. (2008), sensory evaluation of ice creams showed that the low-fat ice cream had a better taste and texture than did the control. In that study, it was claimed that, besides its health benefits, inulin also improved the taste and the texture of the low-fat ice cream (Aykan et al., 2008). Similarly, other studies reported that samples containing inulin as a fat replacer had higher scores for creamy, fatty, and smooth texture attributes in ice cream and frozen ice (Cho and Prosky, 1999; Boeckner et al., 2001; Koole and Meyer, 2001). The consumer acceptability of several low-fat foods containing inulin, such as ice cream, cookies, muffins, cakes, and beef sausages was investigated by Devereux et al. (2003). The results showed that these low-fat foods were rated as acceptable by an untrained test panel but they obtained consistently lower scores than their full-fat counterparts (controls). Regression analysis of that study showed that, unlike the controls, texture was more important than flavor in determining overall acceptability of the low-fat foods (Devereux et al., 2003).

The results of PCA are shown in Figure 3. The PCA was carried out on 2 principal components that were chosen by the common rules (Meullenet et al., 2007). The first principal component (PC1; X-axis) explained $45.3 \%$ of the total variation in the data set. This component points out the contrast of fluffiness with sweetness and yogurt sensory characteristics, such as yogurt flavor, acidity, and astringency. The second principal component (PC2; Y-axis) explained $24.9 \%$ of the total variation and corresponded to the contrast of sandiness with smoothness, creaminess, and vanilla flavor. According to the PCA diagram, the low-calorie formulations approaching the control sample (A) were observed to be sample D (6.5\% inulin $+6.5 \%$ isomalt $)$ and, to some extent, sample C ( $8 \%$ inulin $+5 \%$ isomalt). Sample B was close to the control (A) with respect to $\mathrm{PC} 1$ but showed differences in attributes in the second principal component. On the other hand, samples C, $\mathrm{D}$, and $\mathrm{E}$ were similar to the control (A) with respect to PC2 but showed significant differences in PC1 (Figure 3). The PCA was very useful in investigating the correlations among the attributes and in evaluating the samples all together in general. According to the values obtained by the PCA, some of the descriptors could be correlated (Lawless and Heymann, 1998). For example, creaminess, fatty texture, and smoothness attributes were found to be at the same region. Similarly, yogurt sensory characteristics like acidity, astringency, and yogurt flavor were close to each other and some texture attributes such as hardness, crumbliness, and iciness were found to be at close points on the PCA map (Figure 3).

After 3 mo of storage, the results of the LAB count showed white-colored, single-type colonies in frozen yogurt. The catalase test results were negative for the colonies. Lactic acid bacteria numbers of frozen yogurt samples were found to be in the range of 8.12 to $8.49 \mathrm{log}$. The whole-fat control (A) had significantly more LAB than did samples B (reduced-fat control), C, and D $(P<$ $0.05)$. A decrease of fat and total solids content caused a significant decrease $(0.34 \mathrm{log})$ in the LAB number (A $>$ B). Similarly, Kim et al. (1993) reported higher LAB numbers in frozen yogurt samples prepared with full-fat milk powder than those of samples produced with skim milk powder. The results of the current study showed lower LAB numbers in samples containing 6.5 to $8 \%$ inulin $(\mathrm{C}$ and $\mathrm{D})$, contrary to the findings of Božanić et al. (2002), which showed no effect of inulin on LAB counts of ice cream samples. Despite the fact that slight decreases occur during storage, it is generally expected that traditional yogurt cultures (Strep. thermophilus and L. delbrueckii ssp. bulgaricus; Bielecka et al., 1988; Hui, 1993; Lopez et al., 1998; Var et al., 2000), mixtures of probiotic and traditional yogurt cultures (Davidson et al., 2000; Ordonez et al., 2000), and probiotic cultures (Otero et al., 1996) survive in the frozen yogurt. Survival of LAB after 3 mo of storage of samples is in full alignment with these studies.

\section{CONCLUSIONS}

In the view of the results of the current study, it is apparent that addition of inulin and isomalt allows the production of a frozen yogurt with acceptable flavor and texture attributes, except for the melting quality (the occurrence of very few ice crystals was perceived by the panelists). Such troubles may be overcome by 


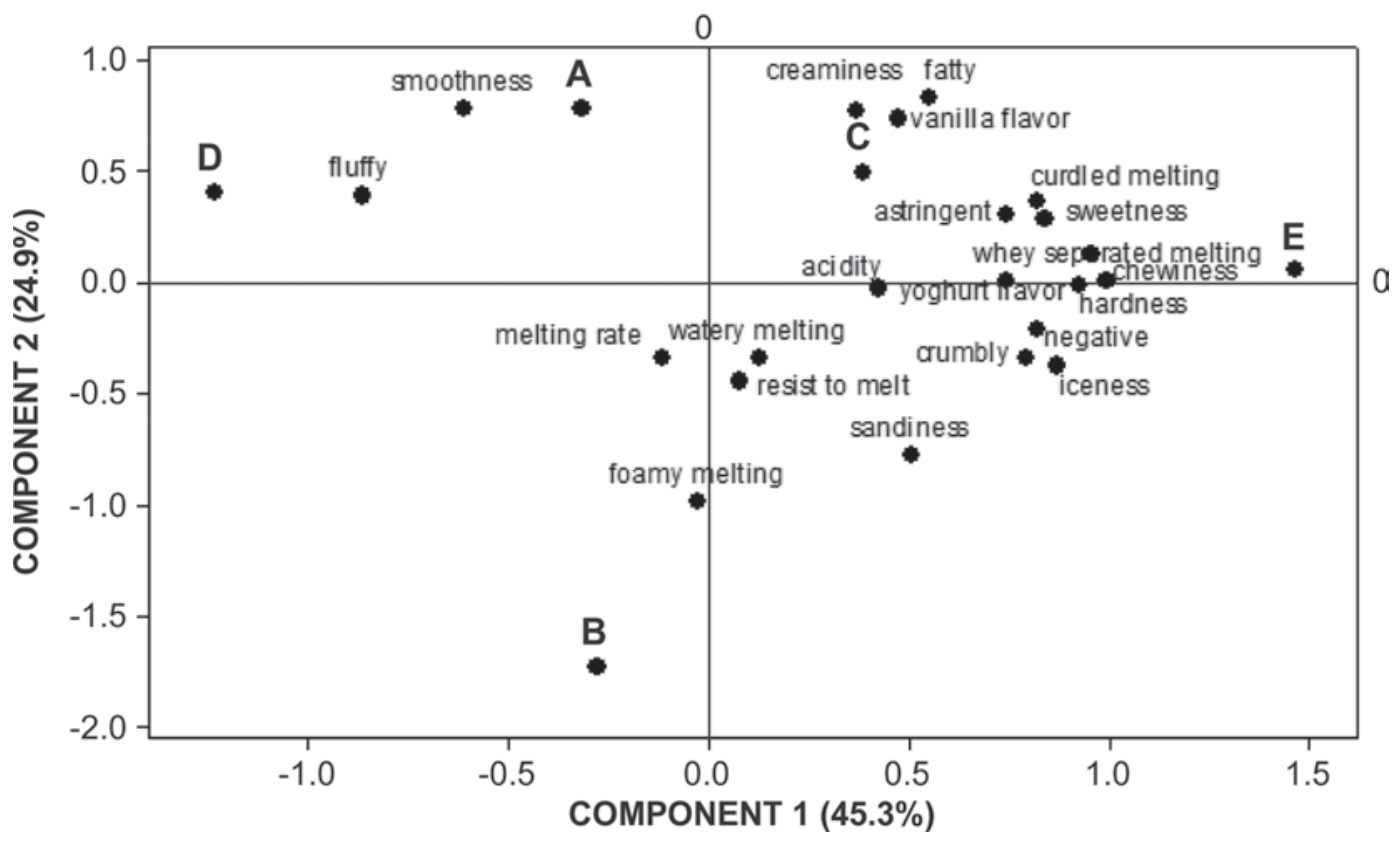

Figure 3. Principal component analysis (PCA) of sensory attributes of yogurt ice cream samples. Sample A = control (with sugar and whole fat), sample B = control (with sugar and reduced fat). Samples C-E had no sugar and reduced fat, and contained $5 \%$ polydextrose and $0.065 \%$ aspartame/acesulfame-K mixture (at a proportion of 70:30). Sample C also contained $8.0 \%$ inulin and $5.0 \%$ isomalt; sample D contained $6.5 \%$ inulin and $6.5 \%$ isomalt; and sample E contained $5.0 \%$ inulin and $8.0 \%$ isomalt.

changing the types and levels of stabilizer/emulsifiers, which, in turn, will positively affect the viscosity. It is possible to produce an attractive frozen yogurt product with the incorporation of inulin and isomalt with no added sugar and reduced fat.

\section{ACKNOWLEDGMENTS}

The authors thank Bil Ergin (Algida, Unilever Inc., Tekirda ğ, Turkey) for his assistance in using the manufacturing plant in addition to his great technical support. In addition, the authors appreciate Kurmed Co. Inc. and Dora Co. Inc. (Istanbul, Turkey) for donating the food additives. We also thank the Istanbul Technical University Food Engineering Department personnel who participated in the sensory tests carried out during the study.

\section{REFERENCES}

Akin, M. S. 2005. Effects of inulin and different sugar levels on viability of probiotic bacteria and the physical and sensory characteristics of probiotic fermented ice-cream. Milchwissenschaft 60:297-300.

AOAC. 2002. Official Methods of Analysis. 17th ed. Association of Official Analytical Chemists, Arlington. VA.

Aykan, V., E. Sezgin, and Z. B. Guzel-Seydim. 2008. Use of fat replacers in the production of reduced-calorie vanilla ice cream. Eur. J. Lipid Sci. Technol. 110:516-520.

Bielecka, M., A. Przewozna, and J. Kowalczuk. 1988. Survival rate of yogurt cultures during production and storage of yogurt ice cream. Acta Aliment. Pol. 14:163-168.
Boeckner, L. S., M. I. Schnepf, and B. C. Tungland. 2001. Inulin: A review of nutritional and health implications. Adv. Food Nutr. Res. 43:1-63.

Božanić, R., I. Rogelj, and L. Tratnik. 2002. Fermentation and storage of probiotic yoghurt from goat's milk. Mljekarstvo. 52:93-111.

Chandan, R. 1997. Dairy-Based Ingredients. Eagan Press, St. Paul, MN.

Cho, S. S., and L. Prosky. 1999. Application of complex carbohydrates to food product fat mimetics. Pages 411-429 in Complex Carbohydrates in Foods. S. S. Cho, L. Prosky, and M. Dreher, ed. Marcel Dekker, New York, NY.

Craig, S. A. S. 2000. Polydextrose: Analysis and physiological benefits. Pages 503-508 in Advanced Dietary Fibre Technology. B. V. McCleary, and L. Prosky, ed. Blackwell Science, Malden, MA.

Davidson, R. H., S. E. Duncan, C. R. Hackney, W. N. Eigel, and J. W. Boling. 2000. Probiotic culture survival and implications in fermented frozen yogurt characteristics. J. Dairy Sci. 83:666-673.

Devereux, H. M., G. P. Jones, L. McCormack, and W. C. Hunter. 2003. Consumer acceptability of low fat foods containing inulin and oligofructose. J. Food Sci. 68:1850-1854.

Downes, F. P., and K. Ito, ed. 2001. Compendium of Methods for the Microbiological Examination of Foods. 4th ed. American Public Health Association, Washington, DC.

El-Nagar, G., G. Glowes, C. M. Tudorică, V. Kuri, and C. S. Brennan. 2002. Rheological quality and stability of yog-ice cream with added inulin. Int. J. Dairy Technol. 55:89-93.

Erkmen, O. 2000. Basic Methods for the Microbiological Analysis of Foods. University of Gaziantep Press, Gaziantep, Turkey.

Franck, A. 1998. Properties and application of chicory inulin. Pages 409-412 in Gums and Stabilisers for the Food Industry. P. A Williams and G. O. Phillips, ed. The Royal Society of Chemistry, Cambridge, UK.

Goh, K. K. T., R. S. Nair, and L. Matia-Merino. 2008. Exploiting the functionality of lactic acid bacteria in ice cream. Food Biophys. $3: 295-304$.

Gostner, A., M. Blaut, V. Schäffer, G. Kozianowski, S. Theis, M. Klingeberg, Y. Dombrowski, D. Martin, S. Ehrhardt, D. Taras, A. Schwiertz, B. Kleessen, H. Lührs, J. Schauber, D. Dorbath, T. 
Menzel, and W. Scheppach. 2006. Effect of isomalt consumption on faecal microflora and colonic metabolism in healthy volunteers. Br. J. Nutr. 95:40-50.

Guinard, J.-X., C. Zoumas-Morse, L. Mori, B. Uatoni, D. Panyam, and A. Kilara. 1997. Sugar and fat effects on sensory properties of ice cream. J. Food Sci. 62:1087-1094.

Guner, A., M. Ardic, A. Keles, and Y. Dogruer. 2007. Production of yogurt ice cream at different acidity. Int. J. Food Sci. Technol. 42:948-952.

Harper, S. J., D. L. Barnes, F. W. Bodyfelt, and M. R. McDaniel. 1991. Sensory ratings of commercial plain yogurts by consumer and descriptive panels. J. Dairy Sci. 74:2927-2935.

Hui, Y. H. 1992. Encyclopedia of Food Science and Technology. Vol. 3. John Wiley Inc., New York, NY.

Hui, Y. H. 1993. Dairy Science and Technology Handbook, Vol. 1 and 2, Principles and Properties. John Wiley and Sons Inc., New York, NY.

Inoue, K., K. Shiota, and T. Ito. 1998. Preparation and properties of ice cream type frozen yogurt. Int. J. Dairy Technol. 51:44-50.

Istanbul Trade Organization. 1985. Dairy Products Seminar. Pages 25-50 in Istanbul Trade Organization Seminar, Publication No: 1987-7, Istanbul, Turkey.

Kaur, H., K. S. Minhas, and U. Bajwa. 2007. Effect of fat replacers and fruit pulp on quality of frozen yoghurt. J. Food Sci. Technol. 44:500-504.

Kim, J. H., Y. H. Kim, S. C. Baick, Y. G. Lee, and J. H. Yu. 1993. Studies on the manufacture of frozen yoghurt made with different mixing ratio of raw milk and whole, skim milk powder. Korean J. Dairy Sci. 15:128-134.

Koole, E., and D. Meyer. 2001. Calorie reduced ice cream and health benefits. Food Ing. Anal. Int. 23:20-22.

Lawless, H. T., and H. Heymann. 1998. Sensory Evaluation of Food, Principles and Practices. Kluwer, Inc., New York, NY.

Lopez, M. C., L. M. Medina, and R. Jordano. 1998. Survival of lactic acid bacteria in commercial frozen yogurt. J. Food Sci. 63:706708.

Macrae, R., R. K. Robinson, and M. J. Sadler. 1993. Encyclopedia of Food Science, Food Technology and Nutrition, Vol. 4. Academic Press, London, UK.

Marshall, R. T., and H. D. Goff. 2003. Formulating and manufacturing ice cream and other frozen desserts. Food Technol. 57:32-45.

Marshall, R. T., H. D. Goff, and R. W. Hartel. 2003. Ice Cream. 6th ed., Kluwer Academic/Plenum Publishers, New York, NY.

Martinou-Voulasiki, I. S., and G. K. Zerfiridis. 1990. Effect of some stabilizers on textural and sensory characteristics of yogurt ice cream from sheep's milk. J. Food Sci. 55:703-707.

McNutt, K., and A. Sentko. 1996. Isomalt offers candymakers new possibilities. Candy Ind. 161:46-49.

Meilgaard, M., G. V. Civille, and B. T. Carr. 2007. Sensory Evaluation Techniques. 4th ed. Taylor and Francis, Boca Raton, FL.

Meullenet, J.-F., R. Xiong, and C. J. Findlay. 2007. Multivariate and Probabilistic Analyses of Sensory Science Problems. Blackwell Pub., Ames, IA.
Ordonez, G. A., I. J. Jeon, and H. A. Roberts. 2000. Manufacture of frozen yogurt with ultrafiltered milk and probiotic lactic acid bacteria. J. Food Proc. Preserv. 24:163-176.

Otero, M., T. Rodriguez, M. Fernandez, J. Gonzalez, and L. B. Lima. 1996. Frozen yogurt. Alimentaria 278:113-115.

Özdemir, C., M. Demirci, S. Özdemir, and O. Sagdic. 2005. Production and some properties of yoghurt ice cream in Turkey. Milchwissenschaft 60:419-422.

Poste, L. M., D. A. Mackie, G. Butler, and E. Larmond. 1991. Laboratory Methods for Sensory Analysis of Food. Canada Communication Group, Pub. Centre, Ottawa, ON, Canada.

Prindiville, E. A., R. T. Marshall, and H. Heymann. 1999. Effect of milk fat on the sensory properties of chocolate ice cream. J. Dairy Sci. 82:1425-1432

Prindiville, E. A., R. T. Marshall, and H. Heymann. 2000. Effect of milk fat, cocoa butter, and whey protein fat replacers on the sensory properties of low fat and nonfat chocolate ice cream. J. Dairy Sci. 83:2216-2223.

Radowski, A. 2006. Isomalt in breakfast cereals, granola bars, and muesli. Cereal Foods World. 51:254-256.

Rowan, C. 1998. Inulin-The long chain to success. Int. Food Ing. $1: 36-37$.

Schaller-Povolny, L. A., and D. E. Smith. 1999. Sensory attributes and storage life of reduced fat ice cream as related to inulin content. J. Food Sci. 64:555-559.

Schaller-Povolny, L. A., and D. E. Smith. 2001. Viscosity and freezing point of a reduced fat ice cream mix as related to inulin content. Milchwissenschaft 56:25-29.

Schaller-Povolny, L. A., and D. E. Smith. 2002. Interaction of milk proteins with inulin. Milchwissenschaft 57:494-497.

Singh, J., K. S. Minhas, and U. Bajwa. 2006. Studies on preparation and shelf-life of yoghurt ice cream. J. Food Sci. Technol. 43:656-661.

Soukoulis, C., and C. Tzia. 2008. Impact of the acidification process, hydrocolloids and protein fortifiers on the physical and sensory properties of frozen yoghurt. Int. J. Dairy Technol. 61:170-177.

Specter, S. E., and C. S. Setser. 1994. Sensory and physical properties of a reduced-calorie frozen dessert system made with milk fat and sucrose substitutes. J. Dairy Sci. 77:708-717.

Tamime, A. Y. 2006. Fermented Milks. Blackwell Science, Ames, IA.

Tamime, A. Y., and R. K. Robinson. 1999. Yoghurt Science and Technology. 2nd ed. Woodhead Pub., Cambridge, UK.

TSE. 1992. Dairy ice cream. TSE Standard 4265. Turkish Standards Institute, Ankara, Turkey.

Turkish Ministry of Agriculture. 2002. Rules for general and nutritional labelling of food materials. Notice. No. 2002/58. Turkish Food Codex. Turkish Ministry of Agriculture, Ankara, Turkey.

Var, I., M. Güven, and Z. Erginkaya. 2000. The effect of storage time on the reduction of microorganisms in yogurt ice cream samples. J. Agric. Fac. University of Canakkale. 15:1-6.

Zhenjian, H., and D. Haili. 2003. The formula and technology of the yoghurt ice cream. Food Machin. 6:37-38. 